This article has been accepted to the journal Qualitative Health Research. James, T. G., Coady, K. A., Stacciarini, J. M. R., McKee, M. M., Phillips, D. G., Maruca, D., \& Cheong, J. "They're not willing to accommodate Deaf patients": Communication experiences of deaf American Sign Language users in the emergency department. Qualitative Health Research.

"They're not willing to accommodate Deaf patients": Communication Experiences of Deaf American Sign Language Users in the Emergency Department

Tyler G. James, M.S., CHES ${ }^{\circledR}{ }^{1}$, Kyle A. Coady, B.S. ${ }^{1}$, Jeanne-Marie R. Stacciarini, Ph.D., R.N., FAAN ${ }^{2}$, Michael M. McKee, M.D., M.P.H. ${ }^{3}$, David G. Phillips, M.A., NIC ${ }^{4}$, David Maruca, BAI, BEI Level III Intermediary ${ }^{4}$, \& JeeWon Cheong, Ph.D.1

Affiliations:

1. Department of Health Education and Behavior, University of Florida, Gainesville, FL.

2. Department of Family, Community and Health System Science, College of Nursing, University of Florida, Gainesville, FL

3. Department of Family Medicine, University of Michigan, Ann Arbor, MI.

4. Community Affiliated.

Authorship contributions: Project conceptualization: TGJ, MMM, JC. Funding acquisition: TGJ. Methodology: TGJ, JMRS, MMM, JC. Investigation: TGJ. Formal analysis: TGJ, KAC, DM. Writing - original draft: TGJ, KAC. Writing - review and editing: TGJ, KAC, JMRS, MMM, DGP, DM, JC. Resources: MMM, DGP. Supervision: JC.

Acknowledgements: This project was funded by the Society for Public Health Education's Student Fellowship in Patient Engagement awarded to Tyler G. James. We thank the five anonymous reviewers whose comments helped improve the manuscript. 


\begin{abstract}
Deaf people who use American Sign Language (ASL) are more likely to use the emergency department (ED) than their hearing English-speaking counterparts, and are also at higher risk of receiving inaccessible communication. The purpose of this study is to explore the ED communication experience of Deaf patients. A descriptive qualitative study was performed by interviewing 11 Deaf people who had used the ED in the past two years. Applying a descriptive thematic analysis, we developed five themes: (1) requesting communication access can be stressful, frustrating, and time-consuming; (2) perspectives and experiences with Video Remote Interpreting (VRI); (3) expectations, benefits, and drawbacks of using on-site ASL interpreters; (4) written and oral communication provides insufficient information to Deaf patients; and, (5) ED staff and providers lack cultural sensitivity and awareness towards Deaf patients. Findings are discussed with respect to medical and interpreting ethics to improve ED communication for Deaf patients.
\end{abstract}




\section{"They're not willing to accommodate Deaf patients": Communication Experiences of Deaf American Sign Language Users in the Emergency Department}

Effective communication within healthcare environments, particularly in emergency departments (EDs), is integral for efficient and quality patient care. Within the ED, effective patient-provider communication reduces the occurrence of patient safety events, facilitates timely diagnosis and treatment, and enables high-quality discharge (Betancourt et al., 2012; Johns Hopkins University \& Armstrong Institute for Patient Safety and Quality, 2014). However, some patients are at higher risk of experiencing ineffective patient-provider communication and, subsequently, are also at higher risk of receiving poorer quality healthcare. Therefore, these patient populations should be prioritized in research and quality improvement programs to improve the quality of ED care and reduce health disparities.

Over 50 million people in the United States (U.S.) have a detectable hearing loss (Agrawal et al., 2008; McKee et al., 2018), deeming them deaf or hard-of-hearing (DHH). DHH patients may be segmented based on medical characteristics of their hearing loss (e.g., configuration, etiology), or socio-linguistic markers (e.g., primary language). Age of onset, a medical characteristic, may be pre- or post-lingual. Prelingual hearing loss means that the person became DHH before the critical period of language development (i.e., before language acquisition); postlingual hearing loss, after the critical period. Most DHH people in the U.S. have postlingual hearing loss (e.g., age-related hearing loss); therefore, most DHH people use spoken language to communicate. However, a linguistic and cultural minority group within this broader patient group is known as the Deaf ${ }^{i}$ community, who primarily use American Sign Language (ASL) to communicate. Deaf people who use ASL have a shared history, literature and art, and 
culture, and may reject a medicalized view of "hearing loss" in favor of a more culturally appropriate sense of being visually oriented.

Deaf people are at high risk of experiencing health-compromising social determinants of health (e.g., un/underemployment, lower educational attainment) attributable to a system of oppression privileging being hearing in society (i.e., audism; Bauman, 2004). Due to language and cultural differences between Deaf patients and non-Deaf providers (who are predominantly not proficient in ASL), an ASL/English interpreter may be necessary to facilitate communication. Like their international Deaf and/or non-English-speaking counterparts, Deaf ASL-users are at higher risk of experiencing ineffective patient-provider communication in U.S. healthcare settings (Kritzinger et al., 2014; Sheppard, 2013; Steinberg et al., 2006). Inaccessible healthcare communication leads Deaf patients to disengage from primary care services (McKee et al., 2011; Sheppard, 2013), and likely contributes to their higher risk of using EDs (Barnett et al., 2017; McKee, Winters, et al., 2015). Deaf patients may be more likely to use the ED than other sources of care due to the ability to obtain accessible communication supports such as an ASL/English interpreter (McKee, Winters, et al., 2015). However, there is limited evidence suggesting that communication is more accessible for Deaf patients in ED settings.

In the U.S., communication accessibility for Deaf patients in medical settings is mandated by federal law. Specifically, healthcare organizations are directed - by Section 504 of the Rehabilitation Act of 1973, the Americans with Disabilities Act (ADA) of 1990, and Section 1557 of the Patient Protection and Affordable Care Act (ACA) of 2010 - to provide services ensuring accessible and effective communication. When patients request interpreting services, hospitals should provide in-person/on-site interpreters or web-based video interpreting services (i.e., Video Remote Interpreting [VRI]). ${ }^{\text {ii }}$ Despite legal mandates, Deaf patients report hospitals 
denying their requests for an interpreter; this leads to Deaf patients experiencing inaccessible and ineffective communication (Iezzoni et al., 2004; Schniedewind et al., 2020; Sheppard, 2013; Silva v. Baptist Health South Florida, Inc., 2017; Sunderland v. Bethesda Health, Inc., 2016). A recent survey among Deaf people in Florida, U.S., found that 37.2\% reported medical facilities denying their interpreter in the past 12 months (James et al., 2021). When interpreters are requested, the ACA requires organizations receiving federal funding (including hospitals accepting government-sponsored health insurance plans) to provide primary consideration to the type of service being requested; that is, does the Deaf patient prefer on-site services or VRI? However, this consideration is not always provided, and VRI services are more commonly used; this is despite patients and advocacy organizations highlighting VRI as being less effective (Kushalnagar et al., 2019), and recommending VRI solely for interim communication until an on-site interpreter is available (National Association of the Deaf \& Deaf Seniors of America, 2018).

There is substantial evidence indicating that medical interpreters improve patient health outcomes and hospital quality metrics for Deaf ASL-users and non-Deaf non-English speaking patients (Bartlett et al., 2008; Karliner et al., 2007; Luan Erfe et al., 2017; Steinberg et al., 2006). Thus, the Agency for Healthcare Research and Quality, and the Joint Commission, have established guidelines for providing these services to patients (Betancourt et al., 2012; The Joint Commission, 2010). However, there is little record of the communication experiences of Deaf patients in the ED. Among non-English-speaking populations, over $80 \%$ of patients who request language assistance in the ED are not provided communication aids, such as interpreters (Taira \& Orue, 2019); yet, this is unknown for the Deaf community. Existing literature is limited due to (1) the focus on unique geographic settings where on-staff medical interpreters and/or ASL- 
fluent providers are available, (2) datedness prohibiting us from understanding if recent policy changes (e.g., ACA) may have improved access, and (3) focus on settings other than the ED. As Deaf patients are at higher risk of using the ED than non-Deaf patients, it is imperative to understand their communication experiences in the ED to determine the need for quality improvement. Thus, the purpose of this study is to describe ED communication experiences of Deaf patients who have used EDs in North Central Florida within the past two years.

\section{Methods}

This study used a descriptive qualitative design as described by Sandelowski (2000, 2010). In designing this study, we applied a transformative paradigm lens. The transformative paradigm, promoted by Mertens $(2007,2009)$ through her work with the Deaf community, seeks to interrogate realities of oppression and promote social justice. The transformative paradigm calls for investigators to work with communities affected by the research question, use qualitative methods to capture the complexity of the problem, and guides appropriate sampling

methods and frames for interpreting findings. All study procedures and materials were approved by the University of Florida Institutional Review Board.

\section{Study Setting}

This study focused on experiences of adult Deaf patient communication with healthcare providers in the ED, within a city in the North Central Florida region, in the U.S. This small city is home to a large-university academic medical center (AMC) in addition to a privately-owned hospital and a Veterans Administration Health System hospital. The AMC operates three adult ED locations comprising of the main ED (a Level 1 Trauma Center) and two ED centers; the private hospital operates a main ED and two freestanding ED centers. Importantly, the North Central Florida context is different from that of other studies investigating Deaf patient 
communication and healthcare access in the U.S. (e.g., Rochester, NY and Ann Arbor, MI; see Supplemental Table 1; McKee et al., 2011; McKee, Winters, et al., 2015; Steinberg et al., 2006). Whereas hospitals in Rochester, NY and Ann Arbor, MI employ staff ASL interpreters and ASLfluent medical providers, no hospital in this study's setting employ staff interpreters nor (to our knowledge) ASL-fluent providers; instead, hospitals rely on community-based organizations (CBOs) to provide ASL interpreters. There is only one CBO based in this city that provides ASL interpreters for a 17-county area in North Central Florida. Further, on-site ASL interpreters (through this $\mathrm{CBO}$ ) are typically contacted by hospitals after VRI services are attempted.

The transformative paradigm encourages identifying different realities and examining the consequences of accepting, and privileging, one version of reality that may be used to harm individuals and communities (Mertens, 2013, p. 31). Therefore, we assume that literature and anecdotes from more accessible hospital contexts (e.g., hospitals where there are on-site/on-staff ASL interpreters) misrepresents the reality experienced by Deaf patients in less accessible hospitals. Recent litigation in Florida and throughout the U.S. (Huffman v. Univ. Med. Ctr. Mgmt. Corp., 2017; Silva v. Baptist Health South Florida, Inc., 2017; Sunderland v. Bethesda Health, Inc., 2016) indicates that when on-staff hospital interpreters are unavailable, Deaf patient communication rights may be violated. Therefore, the present context appears more representative than EDs with on-staff interpreters, thus providing the opportunity to expand the literature by more thoroughly representing Deaf patients' communication experiences in the ED.

\section{Sample and Recruitment}

We applied a purposeful sampling strategy for this inquiry while also prioritizing diversity within the sample (Mertens, 2009). To be eligible for the study, participants must have (1) self-identified as being DHH (i.e., culturally Deaf, hard-of-hearing, hearing impaired, 
DeafBlind, or Deaf plus another disability); (2) reported using ASL as their primary form of communication; (3) reported being 18 years or older; and, (4) have been a patient, or have been the parent of a pediatric patient, in the ED during the past 24 months. Therefore, we focused not on the prospective participants' self-identification with Deaf cultural norms but their primary language modality being ASL. Participants were recruited through social media, community organizations, and peer-to-peer referral.

When approaching sample size, we took into consideration concepts of information power (Malterud et al., 2016) including the aim of the study, longevity of community engagement including previous relations among participants and the interviewer, and analytic strategy employed; recommended sampling adequacy standards for descriptive qualitative studies (Bradshaw et al., 2017); previous studies focusing on Deaf patient access to healthcare (Iezzoni et al., 2004; Kritzinger et al., 2014; Sheppard, 2013); and available study resources. To this end, we aimed to recruit 10 to 15 participants.

Participants received a $\$ 30$ gift card for their participation in the study. In total, 15 were screened as eligible. Some (4) participants were unavailable for interview appointments or dissatisfied with the small financial incentives, leaving 11 participants to be interviewed.

\section{Data Collection Procedures}

The semi-structured interview guide (see Table 1) was developed based on the literature, and the authors' work in advocacy, interpreting, and primary care for Deaf people. The interview guide was piloted with a prospective participant; the interview guide was not substantially revised, and the interview data were included in this analysis.

All interviews were conducted in ASL by the primary author, who is a non-Deaf, ASLfluent, doctoral candidate and Certified Health Education Specialist who has experience applying 
community-engaged research methods to questions of health equity. Before this study, he had been involved in the regional Deaf community for over four-and-a-half years. The interviewer had personal and professional relationships with local Deaf community members and was routinely involved in community-led advocacy. Indeed, he knew 9 of the 11 participants prior to the interview. Data were collected between December 2018 and July 2019. Data collection occurred in the location preferred by the participant (i.e., in an interview room in a research office on a college campus or in the participants' homes through videoconferencing). On the day of the interview, participants completed a written informed consent and video consent form. All but one participant consented to be video recorded, citing confidentiality concerns.

Closed-ended questions, asked before the semi-structured interview, included a brief demographic questionnaire and a health literacy measure. Health literacy is a core construct when considering patient-provider communication, and research has indicated that Deaf ASLusers have lower health literacy than non-Deaf English-speakers. The interviewer administered the video-based ASL version of the Newest Vital Signs (McKee, Paasche-Orlow, et al., 2015; Weiss et al., 2005): a brief, 6-item health literacy measure operationalized through comprehension of a nutrition label. The measure was scored as inadequate (0-1 correct answers), at-risk for inadequate (2-4 correct), and adequate (5-6 correct) (Weiss et al., 2005).

Before, during, and after the interview, the interviewer made analytic and reflexive memos to round off thoughts and analytic considerations. After the completion of an interview, video files were securely transmitted to an out-of-state nationally certified ASL/English interpreter who translated the videos into spoken English. English audio recordings were transcribed verbatim and cross-checked with the original videos by the interviewer prior to data analysis. 


\section{Data Analysis}

Individually, two researchers free-coded the first interview transcript, then met to discuss coding categories used to generate a codebook. The preliminary codebook was used by coders who separately coded interview data using MAXQDA2020 (VERBI Software, 2019). The coding process required coders read the transcript to familiarize themselves with the data and complete an additional reading wherein they applied codes and developed analytic and reflexive memos. After coding was complete, coders discussed section-by-section coding decisions, including the development of new codes; coding discrepancies were discussed and resolved based on consensus, and transcripts reassessed to ensure fidelity to the final coding scheme. Coding categories were collapsed into specific themes based on our original research question. Code relation frequencies were used as a secondary tool to ensure appropriate context for each theme. After themes were developed, participants were interviewed for a synthesized analyzed data member-checking interview (Birt et al., 2016). Notes from these interviews were recorded on an electronic document and integrated into the participant's unique record. An additional member-checking interview was conducted with a key informant: a Deaf person from a separate geographic region of Florida who works as a Deaf interpreter throughout the state.

\section{Results}

The frequency of ED use in the past two years among the 11 participants ranged from two times to over ten times (see Supplemental Table 2). There was heterogeneity in the sample based on self-identifying as culturally Deaf, age of onset of deafness, and preferred language in everyday life. The median length of interviews was 42 minutes. Five themes describe the ED communication experiences of Deaf participants: (1) requesting communication access can be stressful, frustrating, and time-consuming; (2) perspectives and experiences with Video Remote 
Interpreting (VRI); (3) expectations, benefits, and drawbacks of using on-site ASL interpreters;

(4) written and oral communication provides insufficient information to Deaf patients; and, (5)

ED staff and providers lack cultural sensitivity and awareness towards Deaf patients. Each theme is described in-depth using categories and representative participant quotes (see Supplemental Table 3 for an overview of themes).

\section{Requesting Communication Access Can be Stressful, Frustrating, and Time-Consuming}

The most predominant theme identified in the data was the stress and frustration experienced by Deaf participants when requesting communication access in the form of an onsite interpreter. This theme was further categorized into the following: (1) negotiating access; (2) requests fulfilled with VRI; and, (3) friends and family as proxy interpreters.

Negotiating access. The primary category associated with requesting communication access was the negotiation for an interpreter between Deaf participants and ED providers/staff. Upon arriving at the ED, most participants requested on-site (not VRI) interpreter services. Deaf participants reported feeling distressed with the interpreter request process and questioned why they were required to request an interpreter despite clear documentation of their preferred language in the electronic medical record used by the ED.

It is a stupid system that I have to request the interpreter while I'm feeling sick... it says in my chart that I am Deaf and that I need an interpreter... I don't understand why I have to [request an interpreter] while I'm sick.

Deaf participants used a variety of modalities to request an interpreter, including verbally requesting, writing the request on their phone or paper, gesturing, or providing advocacy cards describing their rights under the ADA, such as the cards provided by the National Association of the Deaf (www.nad.org/VRI-card). 
Some participants described waiting for hours - at times up to eight hours - for interpreters to be provided. Most participants stated that on-site interpreters were never provided. In particular, a participant who used the local EDs frequently over the past 15 years stated they had never been provided an on-site interpreter. Deaf participants' recurrent experiences of being refused on-site interpreters led some to no longer request access through an interpreter or outright delay ED care-seeking.

I just don't even try [to request an interpreter]...I've learned it just wasn't worth trying to...The staff isn't really willing to work with me, or they're not willing to try and get an on-site interpreter there...I've learned that it's honestly just not worth the struggle...I try to avoid the emergency room as much as I can because of that.

Requests fulfilled with VRI. After participants requested on-site interpreter services, these requests were rarely fulfilled but VRI was always presented as an option. Deaf participants reported their on-site interpreter requests were denied because interpreters were not on staff at the hospital, were "hard to find," or otherwise unavailable.

I told the doctor, 'I am Deaf, I can't hear what you're saying.' And they said, 'Sorry, we don't have any interpreters here.' And I said, 'Well, you need to understand that I need an interpreter.' They said, 'Well, we have VRI if you want to use that.'...they just kept saying that they didn't have [on-site] interpreters, they only have VRI available.

Participants acknowledged the lack of interpreters in the local area, with most medical interpreters commuting from larger, nearby metropolitan areas.

In contrast to the long wait times for on-site interpreter services, participants shared experiences of short wait times between their interpreter requests and the provision of VRI. 
When Deaf participants saw the VRI machine, they reiterated their request for an on-site interpreter.

I went to the ER and I asked to get an interpreter - a live [on-site] interpreter. They said 'ok.' They did my blood pressure and stuff, and then wheeled in the VRI. I didn't ask for that. I wrote down again that I asked for a live [on-site] interpreter. They said that the

VRI was the live interpreter...they kept trying to stick with the VRI.

Subsequent requests for on-site services were denied, and Deaf participants reported feeling compelled to use the VRI or attempt to use a different modality (e.g., written or spoken language).

Participants also suggested that hospitals failed to provide on-site interpreters because ED staff and providers refused to call the interpreter referral agency.

Sometimes they don't even make the call, they'll put it off...then they finally come back with VRI. And it's just always such a frustrating experience. I try to tell them I don't want to use the VRI but...they say 'Uh, we can't [bring in an on-site interpreter], we don't have the time for that. There's too many other patients we have to see.'

Participants discussed similar experiences of being told on-site interpreters were also not available after-hours. However, they also indicated this information was incorrect and provided the after-hours contact information for the local agency. Still, ED staff and providers did not procure on-site interpreters. Participants reported this inconsistent and contradictory information as detrimental to their overall experience and reducing their trust of ED care team members.

Friends and family as proxy interpreters. When participants reiterated their wish to forgo using VRI (for reasons discussed in Theme 2), Deaf participants reported being frequently pressured by providers and staff to use a proxy interpreter. This happened when Deaf 
participants arrived at the ED with their friends or family members who were asked to interpret in lieu of any professional services (either VRI or on-site).

I walked right up to the secretary's desk and told her that I was Deaf...I told her I did not want VRI, I wanted a live [on-site] interpreter. And then she told me after that, that my [family members], who sign, should sign for me because she saw my [child] signing to me. So, she was saying that my [child] should be interpreting for me... [Interviewer: Is your [child] a trained interpreter?] No, [they're] a kid!

This led Deaf participants to feel that their protected accessibility rights were violated. Many also added that they felt their family members and friends were being taken advantage of as proxy interpreters. In some situations, Deaf participants reported their Deaf friends were asked to interpret. This was a common occurrence among participants who could communicate through both ASL and spoken English - who all shared they had both used a Deaf friend as an interpreter and also interpreted for a Deaf friend.

Deaf participants reported confidentiality concerns when using friends and family members as proxy interpreters:

I really don't like [my family] to know my personal business. Um, I prefer having interpreters who have to be confidential instead of using my [family].

Deaf patients expressed that family members were coerced into providing proxy interpreter services after on-site services were requested and denied, and VRI services were deemed unsuitable after experiencing multiple technical difficulties. The Deaf participant (quoted above) explained that they were presented with the choice of 'using a family member' or 'not having communication access.' 
In addition, there were concerns among Deaf participants regarding the translation accuracy by untrained family members serving as proxy interpreters. In some cases, participants felt the communication was subpar and as though an interpreter was not even present; therefore, the family/friend interpreted communication was not effective. Participants reported this was due to the technical expertise required to interpret, including knowledge of specialized medical vocabulary.

You have the interpreter who is - who is relaying all of the information. All of the content, the expressions, the way it's said. My [family], they don't do that. They listen to the message, and then they interpret it afterwards - they can't do it simultaneously. And I wasn't getting access to all of the information. They would say what they knew the signs for and leave out the rest.

There was also discussion of undue burden on friends and family members asked to interpret during sub-optimal situations. For example, Children of Deaf Adults (CODAs) may feel expected to ensure their Deaf parent has access, placing them in a complex situation of being a part of their support system or focusing on medical communication.

Sometimes my [adult child] will interpret for me but, you know, that's not [their] job. And it can make [them] feel stressed too, because it's [their] dad who's sick. So, trying to figure out which role [their] in - a family role, or should [they] be working with the doctor to communicate...it can be tough for [them].

Deaf people who served as proxy interpreters for Deaf friends also recounted feeling stressed, aware they were not a trained interpreter, and worried about the accuracy of the message being interpreted.

\section{Perspectives and Experiences with Video Remote Interpreting}


Participants described their experiences with VRI as diminishing the potential for effective communication. This theme establishes that the use of VRI diminishes patient-centered care and communication, but may be appropriate in some situations for some patients.

Diminished patient-centered care and communication. Of note, none of our participants preferred the use of VRI in the ED. Participants described that when VRI services were provided they felt emotionally uneasy, "stressed and tense." This was attributed to previous traumatic experiences of VRI not working, which influenced their current perception of VRI. I've had bad experiences with [VRI] in the past... I couldn't see the screen because I couldn't lean forward far enough to see it. So, it made my communication very difficult, and I didn't really understand what was going on. The screen kept freezing. So, ever since I've refused to use the VRI.

Several participants discussed that they would prefer "anything but VRI" including written communication, which was also reported to be ineffective (see Theme 3). The historical experiences with VRI not working as designed are also present-day barriers. For example, in interviews, participants described that the VRI machine would sometimes not turn on and poor internet connection caused the screen to be pixelated, preventing effective communication. It took thirty to forty-five minutes to log into the system, and then once we were logged into the system, the connection was too choppy for me to see the interpreter or understand what they were saying. So, we spent an hour just trying to get through basic communication while the technology froze and the connection was slow. Participants described that the poor experiences with VRI (e.g., technical difficulties), paired with the negotiation of access and their on-site interpreter request being unfulfilled, created a tense communication environment between them and providers. Participants felt "frustrated with 
the lack of communication" in addition to less prioritized and, at times, ignored by their medical team.

They were paying more attention to the VRI and I'm like, 'Hello. I'm the one in the hospital. I'm in the ER. Why - why are you looking at the machine?' And they were trying to figure out the connection and bringing in a technician to fix it and the nurses were fiddling with it the whole time. And, it felt like - it felt like I wasn't even there. I felt like I was just being ignored. Like the equipment was more important than my health.

I show up to the ER and then have to watch them struggle with setting up the VRI when I asked for a live interpreter in the first place. They always try to fix the VRI while I'm sitting there in pain.

In addition, participants described seeing their providers visibly frustrated with the difficulty of setting up and using VRI or waiting for VRI to be procured from a different location of the hospital. VRI ordering issues, including technical difficulties, frequently led to providers and patients writing notes back-and-forth. This approach made Deaf participants feel they were not provided standard, patient-centered care.

(In)appropriateness of VRI. While all participants agreed they would never want VRI to be used, they also indicated that VRI services may be appropriate in some situations. Among some participants, there was recognition that VRI may be needed when an on-site interpreter was truly not available, or during triage before an on-site interpreter arrived.

I think VRI would be fine for maybe a few questions, umm, taking the vitals and getting basic information. I think [VRI] would be fine for that. And then take it out of the room, I 
don't want it in there. Bring in an [on-site] interpreter so they can go more in-depth and I can make sure that I understand everything.

Participants emphasized that VRI should not be used as a replacement for on-site services, and if Deaf patients were not comfortable with using VRI the ED should still provide on-site interpreters.

There were several scenarios that Deaf participants considered inappropriate for VRI to be used. First, participants stated VRI is not effective when in extreme pain. At times, this pain was due to upper-limb injuries resulting in discomfort for Deaf participants. The pain and loss of mobility from their injuries impacted their ability to concentrate on a smaller screen to understand the VRI interpreter. Likewise, the loss of mobility affected their ability to clearly express themselves; these participants reported that it was more difficult for the interpreter to understand them. VRI also presented additional barriers with participants who were DeafBlind or Deaf and low vision who required tactile sign or an on-site interpreter.

The screen is too small. I'm not able to see it very clearly. But the nurse never understands that.

Importantly, when asked if they would consider using the VRI if the screen was larger, DeafBlind participants indicated they would be unwilling because they know it does not provide effective communication. One participant mentioned they require an interpreter who is experienced in tactile American Sign Language (TASL); TASL is different from visual ASL in that signs are produced using a hand-over-hand approach allowing the person to tactually feel the signs being made. VRI, being a computer, is unable to provide this.

\section{Expectations, Benefits, and Drawbacks of Using On-Site ASL Interpreters}


Participants discussed increased patient engagement and shared decision-making when an interpreter was present (in ED or other healthcare settings), specific benefits and expectations of on-site interpreters, and how interpreter behavior may decrease the effectiveness of patientprovider communication.

Increased patient engagement. Deaf participants stated a substantial benefit of having an on-site interpreter was increased engagement with providers - being able to understand their medical condition and being able to ask questions - which helped them understand their health issues and feel more comfortable with making healthcare decisions.

With an interpreter there, I can communicate with the doctors. I can make decisions about my health. With VRI or writing, I don't have enough information. I need more information, and they never provide it unless I have an interpreter.

Without an interpreter present, participants described feeling uncomfortable and lacking the confidence to communicate with their medical team. This was primarily attributed to the language-based power differential - with the Deaf ASL-fluent patient attempting to formulate and explain their questions in English, and then understand the information being provided by providers.

It's easier to ask the doctor questions when there's an interpreter because it's easier to get an answer. When I'm writing, it's harder to express what I want to ask and find the right words. I have to work overtime to figure out what words I wanna use and try to explain the questions I'm asking or understand what they're saying... With the interpreter, I don't have to deal with any spelling or anything, we just sign it and then they can just interpret for the doctor very easily. I'm a lot more comfortable with the interpreter, and I do think I ask more questions than when I'm writing. 
Benefits of on-site interpreters over VRI. Participants discussed several benefits of onsite interpreters over VRI. Specifically, being able to effectively establish rapport with the interpreter and having continuity of interpreted information.

I can't really feel a connection with the interpreter when they're on the screen. If there's an interpreter [in the ER], in person, that's great. It's harder for me to form that connection with them when they're on the screen.

This type of connection can be beneficial to both the Deaf patient and the interpreter, thus directly impacting patient-provider communication. For example, the interpreter can become familiar with the accent and signing style of the Deaf patient to interpret more effectively. For Deaf participants, they were able to establish trust which reduced stress and allowed them to focus on conveying their concerns to providers without fear of a message being conveyed inaccurately. Further, Deaf participants stated that on-site interpreters can provide continuity of information as the same interpreter stays on-site for a specific length of time; VRI interpreters switch every time ED staff see a patient.

They bring it up and it has a list of different languages to pick, so every time we get a new interpreter, we explain what's going on, give a brief summary, and then the doctor can start to talk... With the VRI, you have to reintroduce a new person to the situation, and it can be frustrating.

Interpreter continuity reduces Deaf patient frustrations with sharing medical information across multiple interpreters, and also influences the interpreting process - VRI interpreters are from a variety of regions and their signing accent/dialect may also be region-specific. For example, during member-check interviews, the same interviewee (quoted above) described their experience using VRI with an interpreter from a different region: 
The VRI interpreter was from Arkansas. They had a lot of signs that I didn't understand, and acted way too expressive and treated me like I didn't know ASL...They treated me like I was low functioning, and it diminished my communication.

However, continuity could have different impacts depending on the setting. In healthcare, continuity of interpreters may improve the care experience and interpreting product. However, in interpreter-limited environments - like in this study's setting -where the same interpreter may interpret a college or vocational training course, a job interview, and an ED encounter, a single interpreter having access to a Deaf person's entire life may compromise their privacy.

\section{Interpreter behavior that harms patient-provider communication. Several}

participants raised concerns regarding interpreter behavior that negatively impacted their communication and trust. One major concern was related to confidentiality after an interpreter took a photo in a Deaf patient's room at a regional hospital.

One interpreter at the hospital in [a neighboring city], uh, took a selfie of [themselves] in the ER...it can be hard to trust interpreters when they do stuff like that.

This participant discussed at length the importance of keeping their medical information private, and their fear interpreters would share information - intentionally or unintentionally - with the broader Deaf community; this concern, with this specific interpreter, was echoed by others.

Participants also shared concerns with interpreters maintaining professional and personal boundaries, particularly when it comes to advocating for the patient or asking interpreterinitiated questions to providers.

The [interpreter] kept crossing the line. And they kept asking the doctor things, and I had to tell them to stop, that it's not their job to ask the doctor. It's my job to ask the doctor, and you are just here to interpret. And he was just over embellishing everything that was 
being said, providing too many examples and giving his own opinion, and it was just not good...[On-site] interpreters can show that they care more. And then, they can clarify with me before trying to get more information from the doctor or anything, but involve me more in the communication process.

An additional fear discussed was interpreter-directed bias and discrimination towards a Deaf patient based on the medical content discussed. For example, participants described fear of bias or judgment from an interpreter after informing the medical provider about their sexual orientation or sexual behavior.

Expectations of on-site ASL interpreters. As mentioned above, interpreters can engage in behavior that crosses patient-preferred boundaries and, thus, impedes patient-provider communication. Participants prefer interpreters "show that they care, but still maintain boundaries" and, in doing so, maintain ethical behavior. Similarly, participants indicated interpreters should defer to them when determining access logistics (e.g., interpreter placement and schedules) and determining the appropriate language modality to use, and be qualified to interpret in that modality.

Participants also discussed the importance of an interpreter who is fluent in both ASL and English. This included statements of the importance of clearly conveying medical concepts, and being proficient in interpreting information from patients to providers.

[I prefer someone] certified, or somebody who's qualified and who understands medical terms and is skilled in the medical field so they can facilitate communication as clearly as possible. 
Participants also indicated issues with specific community interpreters who have difficulty interpreting from ASL to English (as assessed by the participant); when asked, participants stated these interpreters do work in medical settings.

\section{Written and Oral Communication Provides Insufficient Information to Deaf Patients}

In the absence of on-site or VRI services, providers routinely resorted to written and oral communication. However, there was widespread agreement among participants that these modalities are largely ineffective. This theme will be presented using the following categories: written communication during the diagnostic and treatment process, spoken language and lipreading, and inaccessible discharge documents.

Written communication. Participants who discussed writing with providers also mentioned that written communication provided limited information, and that information conveyed was dense with medical terminology. Of note, 10 of the 11 participants scored as having at-risk/inadequate health literacy; during interviews, however, some participants had higher health knowledge related to their specific health conditions. Although participants indicated differences between the specificity of the English vocabulary preferred and the amount of information provided, they agreed that written communication was ineffective.

We have to write back and forth to try to communicate. And [ED providers are] using all these big English words that I just don't understand. I have to ask the meaning over and over again, and it's just such a waste of energy and effort, and it's just always so emotional, stressful, and frustrating just trying to communicate with them. Just so they can get an understanding of what I want.

Another participant mentioned that the limited nature of written communication diminished their ability to provide informed consent. 
I had to sign the informed consent but, you know, it wasn't clear what the risks were. I thought it was a common procedure...I'll ask them about the risks or something, 'What are the average risks for the procedure?'And they say, 'It's pretty normal.' And, you know, I assume it's safe based on that response.

This participant recounted the discussion of risks and informed consent occurred without an interpreter present, and they felt disempowered to ask questions by writing.

Spoken language and lipreading. Participants who use hearing aids indicated that, although they prefer an on-site interpreter, they used spoken language and lipreading when in the ED. These methods, however, were not reported as effective for all participants. When participants did lipread, there were several reported challenges to effective communication including accents, personal protective equipment, and room set-up.

I have to remind them very often that I can't hear them, so whenever they have their face covered with that mask or whatever I can't understand what they're saying. Or, if they look away to type on the computer and they keep talking, I miss that information. So, I have to remind them to look at me so I can read their lips and understand what they're saying.

Discharge instructions are inaccessible. One area of particular concern during the ED encounter was the communication process at discharge; participants described this communication as sub-optimal and, at times, non-existent.

They'll give me prescriptions and just send me on my way without explaining anything about what is going on. There's no communication. I have to wait until I see my primary care doctor for them to explain what I'm supposed to do with all these medications that the ER's giving me...I don't know everything about what's going on with my health. 
This was described as the typical experience among participants. Throughout the interviews, participants discussed reliance on primary care providers - who were all described as being adept at communicating - to learn basic information about their condition and understand their treatment plan.

\section{ED Staff and Providers Lack Cultural Sensitivity and Awareness Towards Deaf Patients}

This final theme describes the impact of ED provider/staff knowledge and behavior on the communication experience. This theme is categorized based on healthcare providers attempting to prescribe ineffective communication modalities, staff and providers being inconsistent when applying health system policies, and a lack of provider and staff awareness of working with Deaf patients.

Prescribing communication access. Deaf participants noted that ED providers and staff were consistently prescriptive with communication accessibility, particularly with participants who use both spoken language and ASL.

They were trying to argue with me, thinking that they knew what kind of accommodations I needed, but I told them that I needed an interpreter in order to understand everything that was going on. And they thought, because I was arguing with them, that I could hear, but I had to keep telling them 'I can't hear, I don't know what's happening. Just because I can speak doesn't mean [silence].

This experience was common among Deaf participants who also used spoken language to communicate; however, these participants all reported preferring ASL for medical communication. In addition to these communication assumptions, hospital staff use culturally offensive signage which leads to communication misunderstandings. 
They put the sign up on the wall that says you're hard-of-hearing - 'the patient is hardof-hearing, speak loud.' But, I can't hear them. I'm completely deaf. I don't know why they have the hard-of-hearing sign. I try to tell them but still people come in talking to me or screaming at me - and I try to tell them. It's just frustrating.

This leads to ED providers and staff relying on ineffective communication modalities, causing additional stress on the patient, invalidating the Deaf person's cultural identity and preferred language.

Inconsistent policy application. Deaf participants recognized that policies were inconsistently applied across health systems and at specific locations. One participant described the differences in accessibility within different ED locations ran by the same health system: [ED center 1] wouldn't provide an interpreter, they made me use the VRI...But [the main hospital], I had gone there four times... They were trying to hurry me out, but I told them I needed an interpreter in order to communicate. But they were trying to tell me that [the agency] was closed, and they couldn't provide an interpreter at the time. I told them, 'Yes, they have a number you can call after hours.' And they said, 'No, we don't have that number.' So again, I felt forced to use the VRI...[ED center 2] was the only ER that actually provided an interpreter.

Deaf participants reported that inconsistent policies across health systems caused additional stress, and acknowledged that inconsistencies also deter staff from fulfilling interpreter requests.

Lack of awareness of working with Deaf patients. Participants considered effective communication as a primary objective when engaging in healthcare so that they could make the most appropriate, informed decisions for their health. However, they perceived communication was less of a priority for the ED care team. This was primarily attributed to ED staffs members' 
and providers' limited awareness of Deaf culture and appropriate communication modalities to use when working with deaf and hard-of-hearing people.

Participants recounted ED providers and staff lacking skills and knowledge to effectively work with them. When requesting interpreters, participants indicated they were promptly engaged in debate regarding who is legally responsible for providing communication access, and the appropriateness of family and friends as proxy interpreters. When interpreter services, whether on-site or VRI, were provided, Deaf participants recalled providers and staff not knowing how to work with the interpreter.

And when the VRI came on, the screen would freeze, or the interpreter would say that they couldn't hear the nurse, they needed the nurse to be closer to the machine, which was just very frustrating...And the nurse would be standing directly in front of the screen talking to the interpreter [blocking my view], rather than talking to me... and the interpreter told the nurse to stand behind the laptop and face me, that way they could hear her.

An additional area of particular concern was the appropriateness of an ED medical team member attempting to use ASL to communicate directly with Deaf patients. Several participants described that the private-hospital system would routinely bring in a nurse who was not fluent in ASL to communicate with the patient.

One time I went in... and I was in so much pain. They called the nurse and I tried to sign to them, but I couldn't sign that much because of the pain. And the nurse tried to sign back, but I could not understand what she was saying because it was too slow and she didn't fingerspell well. 
In this case, a provider or staff member knowing some ASL was not effective. The Deaf patient experiencing pain and the nurse's level of ASL knowledge - as determined by the participant, indicated by the slow signing speed and reliance on fingerspelling - would classify this experience as ineffective communication.

\section{Discussion}

Deaf patients are marginalized by the healthcare system starting the moment they are born (Mauldin, 2016; Schwartz, 2006; Sheppard, 2013). Existing literature indicates that Deaf patients face communication and socio-behavioral barriers to accessing primary care and specialist services, which may be responsible for Deaf patients' more frequent use of EDs (Alexander et al., 2012; McKee, Moreland, et al., 2015; McKee, Winters, et al., 2015). Given Deaf patients' higher rate of ED utilization and higher risk of receiving ineffective communication, understanding the communication context within the ED is of central importance to achieving health equity for Deaf patients. However, the majority of studies focused on Deaf patient healthcare communication were conducted in large metropolitan areas without focus on a specific medical setting. Findings from these studies are not transferrable due to important contextual differences in terms of geographic availability of qualified interpreters, clinical processes, and health system policies.

Participants' experiences portrayed that from the moment the Deaf patient enters the ED, they begin negotiating and advocating for communication access after requesting an on-site interpreter. This stressful, frustrating, and time-consuming experience may exacerbate the Deaf patient's medical condition, impede their provider-patient communication, reduce a patient's comprehension of their medical condition and significantly reduce their satisfaction with ED care. Participants in this study stated their on-site interpreter requests were never immediately 
fulfilled; instead, if their friends/family were with them and knew ASL, they felt coerced to interpret even if they did not have the requisite skill set to facilitate medical communication. This reduces the supporting function of the Deaf patient's friend or family. Further, unlike professional interpreters who are contractually and ethically bound to confidentiality, use of proxy interpreters results in potential privacy loss for the Deaf patient. This presents several ethical and medicolegal considerations regarding patient privacy rights and receiving informed consent for procedures. In the event family/friends were unwilling to interpret or unavailable, hospital staff provided VRI as a first-line service.

Overall, participants indicated EDs in North Central Florida have a strong reliance on VRI services for communication access, to the point of "not even trying" to get an on-site interpreter. A recent study of patient and provider perspectives on VRI usage indicated benefits from the provider perspective included convenience, pricing, and availability (Yabe, 2019). However, our participants experienced staff difficulty operating technology, internet bandwidth, and qualifications of the VRI interpreter limiting the effectiveness of VRI-mediated communication; these difficulties are not unique to our setting (Myers et al., 2021; Yabe, 2019). Furthermore, data indicate that EDs in North Central Florida are providing VRI and it is not meeting performance standards (e.g., staff training, sufficient bandwidth) under the Americans with Disabilities Act. This study represents one of the few in-depth qualitative inquiries focused on Deaf patient healthcare communication since the widespread distribution of VRI services in the late 2000s/early 2010s. Given the reports (both community-based and judicial) of hospital use of VRI, this theme is likely transferrable to other contexts.

Difficulties with VRI lead to a large proportion (59\%; $\mathrm{N}=555)$ of Deaf VRI users rating their experience as unsatisfactory, which is associated with also reporting the VRI interfering 
with sharing health information with the medical provider (Kushalnagar et al., 2019).

Kushalnagar and colleagues (2019) question if this interference is due to the use of an interpreter via VRI or the VRI technology itself; our data suggest both. For example, issues with VRI connectivity prevented Deaf patients from gaining communication access; however, as one participant shared, when they did connect to a VRI interpreter, they felt infantilized and regional sign differences led to confusion. Therefore, based on these Deaf participants' experiences, it stands to reason that VRI provides a perception of access but is not yet realized communication access for all patients. If these systems are used, improvements in VRI system connectivity and staff training when using VRI - including situations when not to use VRI (e.g., for DeafBlind patients, or when minimum standards are not met [National Association of the Deaf \& Deaf Seniors of America, 2018]) - are imperative to improve Deaf patient-centered care and healthcare communication, and meet minimum standards under existing regulations.

Similar to the interference of patient-provider communication caused by both the VRI interpreter and technology, we noted both benefits and barriers to the use of on-site interpreters in the ED setting. It is widely recognized in the Deaf healthcare access literature that providing qualified interpreter services increases patient engagement and can improve health literacy (Schwartz, 2006; Steinberg et al., 2006). Deaf participants in this study clearly defined expectations of a qualified interpreter (e.g., national certification [at minimum]) and were able to identify interpreters working in medical settings who did not meet their qualification standards. Participants' expectation for interpreter certification is at odds with the current political climate in the state of Florida, and much of the U.S., where interpreters are not required to be certified or licensed to work in educational, medical, or legal settings. Overall, U.S. federal law lacks direction in determining if an interpreter is 'qualified' (U.S. Department of Justice, 2014). 
However, using career competencies developed by the National Consortium of Interpreter Education Centers (NCIEC), a qualified interpreter working in the ED would possess competencies relevant to medical and mental health interpreters including fluency in both ASL and English, knowledge of technical vocabulary relevant to the assignment, and skills to promote patient autonomy (Northeastern University Regional Interpreter Education Center \& National Consortium of Interpreter Education Centers, 2007; St. Catherine University CATIE Center \& National Consortium of Interpreter Education Centers, 2008). Yet, Deaf participants described instances of on-site interpreter interference with patient-provider communication including violating privacy protections, usurping a Deaf patient's autonomy, and a lack of fluency; these instances, particularly related to the qualifications of the interpreter, are also observed in other states (Myers et al., 2021).

On-site interpreter interferences add additional stress on the Deaf patient and should be avoided as it contradicts the Code of Professional Conduct of the National Association of the Deaf and Registry of Interpreters for the Deaf (2005) and the Standards of Practice of the National Council on Interpreting in Health Care (2005). This warrants the development and dissemination of approaches to ensure interpreters working in the ED are qualified. These approaches should include stronger preparation of interpreters in interpreter training programs and educating healthcare administrators on the competencies expected of a professional medical interpreter. Furthermore, policymakers should work with Deaf-led organizations to identify policy recommendations for establishing credentialing standards in medical settings.

Like other Deaf patients treated in the ED (Anglemyer \& Crespi, 2018), the lack of effective communication Deaf participants in this study experienced likely affected their care processes. While Deaf patients prioritized communication, they felt ED providers did not 
prioritize communication. Hospitals failing to provide communication access to Deaf patients actively counteracts providers' attempts to engage patients in treatment planning, understanding discharge decisions, and is a barrier to improving Deaf patient health literacy. Cultivating a culture of access and care for Deaf patients compels the inclusion of Deaf patients in cultural competency training for medical preparation programs and continuing medical/nursing education courses, and also an increase in medical providers who are Deaf. In addition, we must reassess hospital policies that empower providers/staff - whom Deaf participants reported as not culturally competent and ignorant of accessible communication modalities - to be the gatekeepers of patient communication access (Sunderland v. Bethesda Health, Inc., 2016).

The Deaf community has experienced centuries of oppression in the U.S. (Bragg, 2001). Still today, Deaf patients experience marginalization in medical environments and prescriptive power dynamics with providers (e.g., Schwartz, 2006). Despite this oppression, an underlying trait of resilience and hope manifests through Deaf patients' self-advocacy to get communication access: providing phone numbers to the local interpreter referral agency, using non-profit advocacy tools, educating providers on their rights to an interpreter, and investing time to question the accuracy of the reasons their requests are denied.

\section{Strengths and Limitations}

This study applied recommended linguistically and socio-politically appropriate methods for working with Deaf ASL-users (Anderson et al., 2018). Specifically, we included coresearchers and community members who are Deaf, collected data in a culturally appropriate modality without the presence of the interpreter, and disseminated findings to the Deaf community prior to the scientific community. However, translation between languages and modalities (i.e., from ASL to written English) occurred before data analysis which may have 
inadvertently introduced translation bias (Anderson et al., 2018). Although we implemented specific procedures to increase the rigor and trustworthiness of data, the findings of this study should be interpreted with regard to the limitations of the sample and design.

To reduce the impact of small sample size, we had prolonged engagement with study participants prior to and during the study. This engagement likely increased trust between the interviewer and participant, and therefore also contributed to the richness of information provided. Further, this research sought to explore ED communication from the perspective of the Deaf patient; therefore, we did not interview ED healthcare providers and staff. This methodological choice is justified based on the underrepresented nature of Deaf community experiences in the research literature and principles of transformative research for social justice (Mertens, 2009). Future research interviewing patients, family members, providers, staff, administrators, and conducting field observations could provide additional and triangulated information regarding barriers at the individual and structural levels affecting Deaf patient ED communication. This study did not interview DHH patients who use other signed or spoken languages to communicate. These patients may also face unique barriers when engaging in the English-dominated health system and ASL-dominated interpreting system in the U.S. Finally, we used the ASL version of the Newest Vital Sign (McKee, Paasche-Orlow, et al., 2015) to screen participants' health literacy. Almost all (10 of 11) of the participants screened as having atrisk/inadequate health literacy; however, during interviews, some participants demonstrated considerable condition-specific health knowledge. Future research should seek to understand the extent and accuracy of Deaf participants' health knowledge to further categorize their health literacy.

\section{Conclusions}


Healthcare systems have a legal and ethical responsibility to protect patients' communication access rights as mandated by the Americans with Disabilities Act. Deaf people in North Central Florida reported communication with ED staff and providers was often inaccessible and ineffective. Providers and healthcare systems failed to provide effective communication in these emergencies resulting in participant-described psychological harms. The loss of communication access systematically diminished participants' ability to engage in shared decision-making about their medical care, increased the likelihood of delaying healthcare when needed in the future, and thwarted community efforts to improve healthcare navigation and selfadvocacy. Therefore, we strongly encourage ED administrators, particularly in contexts similar to this study, to revise their communication access policies through partnership with Deaf patients and Deaf-led advocacy organizations. Revisions should include a focus on decreasing delays between on-site interpreter request and provision, reducing hospital dependence on VRI for Deaf patients unless for triaging or bridging until an on-site interpreter can arrive, partnering with more than one interpreter referral agency, improving staff and provider training and awareness, and considering the hiring of on-site staff interpreters. For providers and staff, we share the most frequent recommendation among our interviewees: "ask us what we prefer." The best way to improve your ability to communicate with Deaf patients, and provide better care, is to defer to your patient and support their accommodation requests. 


\section{References}

Agrawal, Y., Platz, E. A., \& Niparko, J. K. (2008). Prevalence of hearing loss and differences by demographic characteristics among US adults: Data from the National Health and Nutrition Examination Survey, 1999-2004. Archives of Internal Medicine, 168(14), 1522-1530. https://doi.org/10.1001/archinte.168.14.1522

Alexander, A., Ladd, P., \& Powell, S. (2012). Deafness might damage your health. The Lancet, 379(9820), 979-981. https://doi.org/10.1016/S0140-6736(11)61670-X

Anderson, M. L., Riker, T., Gagne, K., Hakulin, S., Higgins, T., Meehan, J., Stout, E., PiciD’Ottavio, E., Cappetta, K., \& Wolf Craig, K. S. (2018). Deaf qualitative health research: Leveraging technology to conduct linguistically and sociopolotically appropriate methods of inquiry. Qualitative Health Research, 1049732318779050. https://doi.org/10.1177/1049732318779050

Anglemyer, E., \& Crespi, C. (2018). Misinterpretation of psychiatric illness in Deaf patients: Two case reports. Case Reports in Psychiatry, 2018, 3285153. https://doi.org/10.1155/2018/3285153

Barnett, S., Matthews, K.A., Sutter, E. J., DeWindt, L. A., Pransky, J. A., O’Hearn, A. M., David, T. M., Pollard, R. Q., Jr., Samar, V. J., \& Pearson, T. A. (2017). Collaboration with Deaf communities to conduct accessible health surveillance. American Journal of Preventive Medicine, 52(3), S250-S254. https://doi.org/10.1016/j.amepre.2016.10.011

Bartlett, G., Blais, R., Tamblyn, R., Clermont, R. J., \& MacGibbon, B. (2008). Impact of patient communication problems on the risk of preventable adverse events in acute care settings. CMAJ : Canadian Medical Association Journal, 178(12), 1555-1562. https://doi.org/10.1503/cmaj.070690 
Bauman, H.-D. L. (2004). Audism: Exploring the metaphysics of oppression. Journal of Deaf Studies and Deaf Education, 9(2), 239-246. https://doi.org/10.1093/deafed/enh025

Betancourt, J. R., Renfrew, M. R., Green, A. R., López, L., \& Wasserman, M. (2012). Improving patient safety systems for patients with limited English proficiency: A guide for hospitals. (AHRQ Publication No. 12-0041). Agency for Healthcare Research and Quality. https://www.ahrq.gov/sites/default/files/publications/files/lepguide.pdf

Birt, L., Scott, S., Cavers, D., Campbell, C., \& Walter, F. (2016). Member checking: A tool to enhance trustworthiness or merely a nod to validation? Qualitative Health Research, 26(13), 1802-1811.

Bradshaw, C., Atkinson, S., \& Doody, O. (2017). Employing a qualitative description approach in health care research. Global Qualitative Nursing Research, 4.

Bragg, L. (Ed.). (2001). Deaf World. New York University Press.

Huffman v. Univ. Med. Ctr. Mgmt. Corp., (United States District Court for the Eastern District of Louisiana 2017).

Iezzoni, L. I., O’Day, B. L., Killeen, M., \& Harker, H. (2004). Communicating about health care: Observations from persons who are deaf or hard of hearing. Annals of Internal Medicine, $140(5), 356-362$.

James, T. G., McKee, M. M., Sullivan, M. K., Ashton, G., Hardy, S. J., Santiago, Y., Phillips, D. G., \& Cheong, J. (2021). Community-engaged needs assessment of Deaf American Sign Language users in Florida, 2018. Public Health Reports (Washington, D.C.: 1974), 333549211026782. https://doi.org/10.1177/00333549211026782

Johns Hopkins University \& Armstrong Institute for Patient Safety and Quality. (2014). Improving the emergency department discharge process: Environmental scan report 
(Publication No. 14(15)-0067-EF). Agency for Healthcare Research and Quality. https://www.ahrq.gov/professionals/systems/hospital/edenvironmentalscan/index.html

Karliner, L. S., Jacobs, E. A., Chen, A. H., \& Mutha, S. (2007). Do professional interpreters improve clinical care for patients with limited English proficiency? A systematic review of the literature. Health Services Research, 42(2), 727-754. https://doi.org/10.1111/j.1475-6773.2006.00629.x

Kritzinger, J., Schneider, M., Swartz, L., \& Braathen, S. H. (2014). "I just answer 'yes' to everything they say": Access to health care for deaf people in Worcester, South Africa and the politics of exclusion. Patient Education and Counseling, 94(3), 379-383.

Kushalnagar, P., Paludneviciene, R., \& Kushalnagar, R. (2019). Video Remote Interpreting technology in healthcare: Cross-sectional study of Deaf patients' experiences. JMIR Rehabilitation and Assistive Technologies, 6(1), e13233. https://doi.org/10.2196/13233

Luan Erfe, B. M., Siddiqui, K. A., Schwamm, L. H., Kirwan, C., Nunes, A., \& Mejia, N. I. (2017). Professional medical interpreters influence the quality of acute ischemic stroke care for patients who speak languages other than English. Journal of the American Heart Association, 6(9), e006175. https://doi.org/10.1161/JAHA.117.006175

Malterud, K., Siersma, V. D., \& Guassora, A. D. (2016). Sample size in qualitative interview studies: Guided by information power. Qualitative Health Research, 26(13), 1753-1760. https://doi.org/10.1177/1049732315617444

Mauldin, L. (2016). Made to hear: Cochlear implants and raising deaf children. University of Minnesota Press. http://ebookcentral.proquest.com/lib/ufl/detail.action?docID=4392072 
McKee, M. M., Barnett, S., Block, R. C., \& Pearson, T. A. (2011). Impact of communication on preventive services among deaf American Sign Language users. American Journal of Preventive Medicine, 41(1), 75-79.

McKee, M. M., Lin, F. R., \& Zazove, P. (2018). State of research and program development for adults with hearing loss. Disability and Health Journal. https://doi.org/10.1016/j.dhjo.2018.07.010

McKee, M. M., Moreland, C., Atcherson, S. R., \& Zazove, P. (2015). Hearing loss: Communicating with the patient who is deaf or hard of hearing. FP Essentials, 434, 24 28.

McKee, M. M., Paasche-Orlow, M. K., Winters, P. C., Fiscella, K., Zazove, P., Sen, A., \& Pearson, T. (2015). Assessing health literacy in Deaf American Sign Language users. Journal of Health Communication, 20 Suppl 2, 92-100. https://doi.org/10.1080/10810730.2015.1066468

McKee, M. M., Winters, P. C., Sen, A., Zazove, P., \& Fiscella, K. (2015). Emergency department utilization among deaf American Sign Language users. Disability and Health Journal, 8(4), 573-578.

Mertens, D. M. (2007). Transformative considerations: Inclusion and social justice. American Journal of Evaluation, 28(1), 86-90. https://doi.org/10.1177/1098214006298058

Mertens, D. M. (2009). Transformative research and evaluation. The Guilford Press.

Mertens, D. M. (2013). What does a transformative lens bring to credible evidence in mixed methods evaluations? New Directions for Evaluation, 138, 27-35.

Myers, M. J., Annis, I. E., Withers, J., Williamson, L., \& Thomas, K. C. (2021). Access to effective communication aids and services among American Sign Language users across 
North Carolina: Disparities and strategies to address them. Health Communication, 1-10. https://doi.org/10.1080/10410236.2021.1878594

National Association of the Deaf \& Deaf Seniors of America. (2018). NAD-Deaf Seniors of America (DSA) Position Statement on Minimum Standards for Video Remote Interpreting Services in Medical Settings. https://www.nad.org/about-us/positionstatements/minimum-standards-for-video-remote-interpreting-services-in-medicalsettings/

National Association of the Deaf \& Registry of Interpreters for the Deaf. (2005). NAD-RID code of professional conduct. Registry of Interpreters for the Deaf. https://rid.org/ethics/codeof-professional-conduct/

National Council on Interpreting in Healthcare. (2005). National standards of ppractice for interpreters in health care. National Council on Interpreting in Health Care. https://www.ncihc.org/assets/documents/publications/NCIHC\%20National\%20Standards $\% 20$ of\%20Practice.pdf

Northeastern University Regional Interpreter Education Center \& National Consortium of Interpreter Education Centers. (2007). Mental healthcare and substance use interpreting domains and competencies. CATIE Center \& NCIEC.

https://healthcareinterpreting.org/mental-health-domains-competencies/

Sandelowski, M. (2000). Whatever happened to qualitative description? Research in Nursing \& Health, 23(4), 334-340.

Sandelowski, M. (2010). What's in a name? Qualitative description revisited. Research in Nursing \& Health, 33(1), 77-84. https://doi.org/10.1002/nur.20362 
Schniedewind, E., Lindsay, R., \& Snow, S. (2020). Ask and ye shall not receive: Interpreterrelated access barriers reported by Deaf users of American Sign Language. Disability and Health Journal, 100932. https://doi.org/10.1016/j.dhjo.2020.100932

Schwartz, M. (2006). Communication in the doctor's office: Deaf patients talk about their physicians [Dissertation, Syracuse University]. https://surface.syr.edu/cfe_etd/7

Sheppard, K. (2013). Deaf adults and health care: Giving voice to their stories. Journal of the American Association of Nurse Practitioners, 26(9), 504-510. https://doi.org/10.1002/2327-6924.12087

Silva v. Baptist Health South Florida, Inc., (Court of Appeals, 11th Circuit 2017).

St. Catherine University CATIE Center \& National Consortium of Interpreter Education Centers. (2008). ASL/English medical interpreter domains and competencies. CATIE Center \& NCIEC. http://www.interpretereducation.org/wpcontent/uploads/2015/02/DomainsCompetencies10-09-08.pdf

Steinberg, A. G., Barnett, S., Meador, H. E., Wiggins, E. A., \& Zazove, P. (2006). Health care system accessibility: Experiences and perceptions of deaf people. Journal of General Internal Medicine, 21(3), 260-266.

Sunderland v. Bethesda Health, Inc., (United States District Court for the Southern District of Florida 2016).

Taira, B. R., \& Orue, A. (2019). Language assistance for limited English proficiency patients in a public ED: Determining the unmet need. BMC Health Services Research, 19(1), 56.

The Joint Commission. (2010). Advancing effective communication, cultural competence, and patient- and family-centered care: A roadmap for hospitals. The Joint Commission. 
U.S. Department of Justice. (2014). Effective communication. Disability Rights Section, Civil Rights Division, U.S. Department of Justice. https://www.ada.gov/effective-comm.htm

Weiss, B. D., Mays, M. Z., Martz, W., Castro, K. M., DeWalt, D. A., Pignone, M. P., Mockbee, J., \& Hale, F. A. (2005). Quick assessment of literacy in primary care: The Newest Vital Sign. Annals of Family Medicine, 3(6), 514-522. https://doi.org/10.1370/afm.405

Yabe, M. (2019). Healthcare providers' and deaf patients' interpreting preferences for critical care and non-critical care: Video remote interpreting. Disability and Health Journal, 100870. https://doi.org/10.1016/j.dhjo.2019.100870 
Table 1

Interview guide with prompts

Can you tell me about a recent time you went to the emergency room?

Example prompts:

1. How did you communicate with staff and providers when you arrived to the ER?

2. Describe how you and your doctor communicated.

3. What was the process for requesting an ASL interpreter?

4. During the past 2 years, what has happened when an interpreter is requested?

5. How do you feel about your communication experience with your doctors in the ER? 
Supplemental Table 1

Comparison of context between North Central Florida and other areas where Deaf health research is conducted.

\begin{tabular}{|c|c|c|c|}
\hline & $\begin{array}{l}\text { North Central } \\
\text { Florida }\end{array}$ & Rochester, NY & Ann Arbor, MI \\
\hline \multicolumn{4}{|l|}{$\begin{array}{l}\text { Academic medical } \\
\text { center characteristics }\end{array}$} \\
\hline ED volume $^{\mathrm{a}}$ & Very High & Very High & Very High \\
\hline $\begin{array}{l}\text { Trauma center } \\
\text { designation }^{b}\end{array}$ & Level 1 & Level 1 & Level 1 \\
\hline ED wait time ${ }^{\mathrm{a}}$ & 31 minutes & 15 minutes & 37 minutes \\
\hline $\begin{array}{l}\text { On-staff ASL } \\
\text { interpreters }^{c}\end{array}$ & No & Yes & 8 \\
\hline $\begin{array}{l}\text { On-staff ASL- } \\
\text { fluent } \\
\text { providers }^{c}\end{array}$ & No & Yes & Yes \\
\hline $\begin{array}{l}\text { Credential required } \\
\text { for interpreters } \\
\text { working in medical } \\
\text { settings }\end{array}$ & No & No & Yes \\
\hline $\begin{array}{l}\text { Number of } \\
\text { interpreters certified } \\
\text { by the Registry of } \\
\text { Interpreters for the } \\
\text { Deaf, within } 50 \\
\text { miles }^{\text {c }}\end{array}$ & 28 & 220 & 143 \\
\hline
\end{tabular}

Note. Data reported in this table were collected in January 2019.

${ }^{a}$ Data source: Centers for Medicare and Medicaid Services, Hospital Compare

(https://www.medicare.gov/care-compare/?providerType=Hospital\&redirect=true).

${ }^{b}$ Data source: American Trauma Society (https://www.amtrauma.org/page/FindTraumaCenter).

${ }^{\mathrm{c}}$ Data source: Personal communication.

${ }^{\mathrm{d}}$ Data source: State law.

e Data source: Registry of Interpreters for the Deaf member registry (https://myaccount.rid.org/Public/Search/Member.aspx). 
Supplemental Table 2

Participant and interview summary characteristics

\begin{tabular}{|c|c|}
\hline Characteristic & $\mathrm{N}=11$ \\
\hline \multicolumn{2}{|c|}{ Participant } \\
\hline Frequency of ED use, past 2 years & Range: 2 to $>10$ times \\
\hline \multicolumn{2}{|l|}{ Identity } \\
\hline Culturally Deaf & 7 \\
\hline Hard-of-Hearing & 2 \\
\hline Other (DeafBlind, Hearing Impaired) & 2 \\
\hline \multicolumn{2}{|l|}{ Age of onset of deafness } \\
\hline Born deaf & 4 \\
\hline Birth to age 3 & 7 \\
\hline \multicolumn{2}{|l|}{ Deaf family members } \\
\hline \multicolumn{2}{|l|}{ Parent or sibling } \\
\hline Extended family & 1 \\
\hline \multicolumn{2}{|l|}{ Preferred language (in everyday life) } \\
\hline $\begin{array}{l}\text { Sign language (ASL, Signed Exact } \\
\text { English) }\end{array}$ & 4 \\
\hline $\begin{array}{l}\text { Sign language, and English or other } \\
\text { spoken language, depending on setting }\end{array}$ & 5 \\
\hline Sign language and Spanish & $(8)$ \\
\hline Preferred language (in healthcare) & S \\
\hline $\begin{array}{l}\text { Signed language (ASL, Signed Exact } \\
\text { English) }\end{array}$ & 11 \\
\hline $\begin{array}{l}\text { Sign language, and English or other } \\
\text { spoken language, depending on setting }\end{array}$ & 0 \\
\hline Sign language and Spanish & 0 \\
\hline Use assistive technology & 6 \\
\hline Age & $M e d=35$ years (range: 31 to 60 ) \\
\hline \multicolumn{2}{|l|}{ Gender } \\
\hline Female & 6 \\
\hline Male & 5 \\
\hline \multicolumn{2}{|l|}{ Race } \\
\hline White & 4 \\
\hline Black & 4 \\
\hline Hispanic & 1 \\
\hline Biracial/multiracial & 2 \\
\hline \multicolumn{2}{|l|}{ Highest level of education } \\
\hline High school diploma & 3 \\
\hline Some college & 6 \\
\hline 4-year college degree or higher & 2 \\
\hline \multicolumn{2}{|l|}{$\begin{array}{l}\text { ASL-version, Newest Vital Sign (health } \\
\text { literacy) score }\end{array}$} \\
\hline Adequate & 1 \\
\hline
\end{tabular}




\begin{tabular}{|l|c|}
\hline At-risk for inadequate & 6 \\
\hline Inadequate & 4 \\
\hline Length & Interview \\
\hline Location & \\
\hline Private room in research office & 82 minutes (range: 27 to 66) \\
\hline Remote - through videophone & 3 \\
\hline
\end{tabular}


Supplemental Table 3

Themes and categories describing Deaf patients' communication experiences in the ED.

\begin{tabular}{|c|c|}
\hline Theme & Categories (Sub-Theme) \\
\hline \multirow{3}{*}{$\begin{array}{l}\text { Requesting communication access can be } \\
\text { stressful, frustrating, and time-consuming }\end{array}$} & Negotiating access \\
\hline & Requests fulfilled with VRI \\
\hline & Friends and family as proxy interpreters \\
\hline \multirow[t]{2}{*}{$\begin{array}{l}\text { Perspectives and experiences with Video } \\
\text { Remote Interpreting }\end{array}$} & $\begin{array}{l}\text { Diminished patient-centered care and } \\
\text { communication }\end{array}$ \\
\hline & (In)appropriateness of VRI \\
\hline \multirow{4}{*}{$\begin{array}{l}\text { Expectations, benefits, and drawbacks of } \\
\text { using on-site ASL interpreters }\end{array}$} & Increased patient engagement \\
\hline & Benefits of on-site interpreters over VRI \\
\hline & $\begin{array}{l}\text { Interpreter behavior that harms patient- } \\
\text { provider communication }\end{array}$ \\
\hline & Expectations of on-site ASL interpreters \\
\hline \multirow{3}{*}{$\begin{array}{l}\text { Written and oral communication provides } \\
\text { insufficient information to Deaf patients }\end{array}$} & Written communication \\
\hline & Spoken language and lipreading \\
\hline & Discharge instructions are inaccessible \\
\hline \multirow{3}{*}{$\begin{array}{l}\text { ED staff and providers lack cultural } \\
\text { sensitivity and awareness towards Deaf } \\
\text { patients }\end{array}$} & Prescribing communication access \\
\hline & Inconsistent policy application \\
\hline & $\begin{array}{l}\text { Lack of awareness of working with Deaf } \\
\text { patients }\end{array}$ \\
\hline
\end{tabular}


${ }^{\mathrm{i}}$ In this article, Deaf is capitalized as it is used as a noun to indicate affiliation with the cultural and linguistic group of the Deaf community (Padden \& Humphries, 1988). Although there are important cultural characteristics to consider, we use the term "Deaf" to be inclusive of any deaf or hard-of-hearing person who uses ASL as their primary language.

ii Video Remote Interpreting (VRI) is an interpreting service where an off-site interpreter is contacted through a computer, iPad, or other mobile device to facilitate communication. The use of VRI for Deaf patients in healthcare environments is releatively recent, with pilot testing occuring in Chicago, Illinois, U.S. in 2010. The Americans with Disabilities Act requires that VRI technology meet the following performance standards: (1) high internet bandwidth to support real-time, full-motion audio and video without grainy or blurry video or poor audio; (2) a clear video image of the interpreter's and Deaf person's face, arms, hands, and fingers; (3) clear transmission of audio; and, (4) adequate staff training for set-up and operation (28 C.F.R. $\S 36.303$ ). 